\title{
Human Postural Adaptation to Earthly and Atypical Gravitational Environment Effects of Sport Training on Stabilometric Parameters
}

\author{
Luisa Pizzigalli $^{1 *}$, Margherita Micheletti Cremasco ${ }^{2}$, Elena Cremona ${ }^{1}$, Alberto Rainoldi ${ }^{1}$ \\ ${ }^{1}$ Department of Medical Sciences, School of Exercise and Sport Sciences, SUISM, \\ University of Turin, Turin, Italy \\ ${ }^{2}$ Department of Life Sciences and Systems Biology, University of Turin, Turin, Italy \\ Email: "luisa.pizzigalli@alice.it \\ Received June $6^{\text {th }}, 2013$; revised July $8^{\text {th }}, 2013$; accepted August $4^{\text {th }}, 2013$
}

Copyright (C) 2013 Luisa Pizzigalli et al. This is an open access article distributed under the Creative Commons Attribution License, which permits unrestricted use, distribution, and reproduction in any medium, provided the original work is properly cited.

\begin{abstract}
Earthly gravitational environment has been conditioned organisms evolutional transformations. Mankind evolution in acquiring the upright posture changed functional anatomical characteristics behaved in an almost stable environment $(g=9.81 \mathrm{~m} / \mathrm{s})$. Technological environment, up to the microgravity conditions, faces peculiar gravitational conditions that may affect locomotion, working capabilities and living situation. To understand human adapting capacities, some systematic knowledge may come from the study of trained persons such as those practising sports in different postures and environments. The aims of this study are to investigate whether long-term practice of a physical activity, in which body attitude and postural regulation are organized in different ways, can influence postural control and generate a "postural memory". Three groups of male athletes (average age: $22 \pm 3$ years, weight: $69 \pm 9 \mathrm{~kg}$, height: $179.6 \pm 5.5$ $\mathrm{cm}$ ) were studied in 26 athletes (runners, bikers and swimmers). The protocol consisted of balance tests with eyes open (EO) and closed (EC) in bipodalic and monopodalic conditions. Bikers showed a mean velocity lower than swimmers both in EO $(p=.004)$ and EC condition $(p=.03)$. Also for mean velocity in M-L plane $(p=.02)$ and for perimeter length $(p=.003)$ during EO condition, bikers showed lower results. Moreover, bikers showed a more posterior position of the centre of pressure when compared to runners with EO $(p=.02)$ and with EC $(p=.03)$. These findings suggested that sport-specific physical training induce postural modifications on upright stance. Within the main results concerning the gravitational aspects appears paramount that swimming, the most $0 \mathrm{~g}$ sport (water is the best terrestrial $0 \mathrm{~g}$ simulator environment) gives the smallest postural memory conditioning. The studies about human postural control in normal condition, about postural modifications and memory induced by specific physical training in normal versus atypical gravitation setting, open a new perspective in anthropological studies on postural adaptations, ability and performance in extreme environments.
\end{abstract}

Keywords: Human Posture; Postural Memory; Environmental Adaptations; Athletes

\section{Introduction}

\section{Evolutional Relationship between Posture and Environment}

Gravitation has played an important role in influencing the evolutionary processes that led to the actual human characteristics (mainly the ones related to by the labyrinth function). Our postures, in terrestrial environment, and even more our locomotion and movement control is the product of a progressive adaptation of the body structures and the functional and control capabilities in relationship to the contrast with the gravitation driving force.

Reconsidering the studies of A. Delattre and R. Fenart (Delattre \& Fenart, 1960) ensues the evidence that Vertebrate labyrinth, the semicircular canals and the whole equilibrium organ, were physiologically oriented in the evolution to detect the

\footnotetext{
*Corresponding author.
}

direction of the gravitation field, regardless of bodies in shape, size and postural orientation, ground-dwelling, water swimming or air flight. Earthly Gravity, the "little g" (g), which is the local gravitational field at the terrestrial surface, is equivalent to the free-fall acceleration $(9.81 \mathrm{~m} / \mathrm{s})$. It is certainly a component of the environment and it may be perceived at a first approximation as a physical constant, something like and frequently confused, with Newton's universal gravitational effective constant, the "big G". At the Earth's surface, the gravitational field shows only instrumental variations, with virtually no effect on the living. Gravity is a weak force (a small magnet attracts a nail against the mass of the planet), nevertheless, the force of gravity has an absolute influence in determining the survival of live animals or plants: no species can survive if it is not adapted to the gravitational environment.

This allows us to discuss Delattre's proposed gravitation and in particular its effect on the equilibrium organ, the "inner ear vestibule", as one of the main factors of the human form evolu- 
tion and its fundamental meaning in the humanization process. The so-called "vestibular plane" (inclined so that when horizontal, the traditional "Frankfort Plane" downslides about $28^{\circ}$ ) gives us a comfortable and safe vision of the ground ahead within the evolution of human postural adaptation as an important, but not unique, step in the complicate "bush-like" pattern of the Primates evolution from the original vertebrate horizontal posture to upright human locomotion and arboreal anthropoid dwelling (Harmon, 2013).

Today in the study of the man/environment changes mainly concern the "living environment" which is increasingly artificial and technology dependant. The new environments, particularly the extreme ones, lead to the possibility of experiencing human capabilities in conditions other than the gravitational ones that have characterized our evolution, as we may experience situations in micro/macro gravity and in the absence of gravity in the Outer Space (Masali et al., 2010a, 2010b).

Fundamentally, to live in the Space environment, a different process of adaptation needs to be applied, one being the aptitude-based selection and training applied by the agencies, another being the adaptation of the environment to support human life in the effort to create a sustainable and Earth-autonomous habitat. In cases where the environment cannot be adapted, there is a third possibility: exaptation. Exaptation, first proposed by Gould and Vrba (1982), means that the "archetypal" structures developed by an organism for a specific need are co-opted by the new environment to evolve into new functions (Gould \& Vrba, 1982; Gould, 1990, 2010) as "different adaptive patterns may derive from unusual environmental conditions. This approach may be the challenge for extraterrestrial adaptation of Earthly organisms".

Ergonomic research to study the elements of the built environment become paramount to better support human activities in Space and in conditions other than $1 \mathrm{~g}$ but also takes care to investigate further possible changes or functional postural adaptations. Man may encounter these new conditions. Here comes the importance of studies in reduced gravity, in real or, when possible, in simulated conditions such as "neutral buoyancy" or "virtual simulation" (Andreoni et al., 2000) or "parabolic flights" (Schlacht et al., 2009a, 2009b, 2009c) simulations of gestures with actions, etc. Most studies on the ground in the sporting arena (Tinto et al., 2012; Rosato et al., 2012) and, as in our study the behavior of balance, control and postural memory etc. which follow the practice of sport activities in extreme environmental conditions and different postures and for sport practitioners, whether a sport-specific balance oriented training can modify athlete strategies during control of static postural balance in different sensory conditions. A persuasive approach to the significance of unconventional gravity conditions and motor activity occurs from some experience of our research team in an ESA Student Parabolic Flight Campaign, during the color perceptive experiment "CROMOS" in which some gymnastics actions were performed by Irene Schlacht and Henrik Birke, during some void parabolas (Schlacht et al., 2009a, 2009b, 2009c). However mostly of our knowledge origins from the encounter with the choreographer, dance educator and researcher Kitsou Dubois in the course of one of her performance in Chambery (Masali et al., 2010a). Kitsou Dubois worked for ten years with the space research on gestures and process orientation and perception in weightlessness. She experienced weightlessness aboard parabolic flights proposed by the French Space Research (CNES) between 1990 and 1994, a flight to Star City in Russia in September 2000 opening a new program with the agency Arts Catalyst-Science which proposed an astronaut training from dance techniques. She was able to participate in more than a dozen parabolic flights and experience weightlessness. K. Dubois is the first artist in the choreographer world who works with the Space research weightless gesture (Dubois, 1994).

Moreover, for sport practitioners, whether a sport-specific balance oriented training can modify athlete strategies during control of static postural balance in different sensory conditions. A relationship exists between balance ability and sport training: athletes of different sports develop specific postural adaptations since specific is the physical activity. Training feedback requires a gravitational stimulation as human adaptation to upright posture is mostly by antagonism to gravity force.

A peculiar aspect of gravitational adaptation is the self perceiving in relationship to space and time.

\section{Postural Control and Physical Activity}

The position of the body in relation to force gravity and the surround is controlled by combining visual, vestibular and proprioceptive inputs (Manchester et al., 1989). Vision is the system primarily involved in planning animal and human locomotion and in avoiding obstacles along way. The vestibular system can be considered as a "naturally embedded gyroscope", since it senses linear and angular accelerations. The somatosensory system can be described as a multitude of sensors which sense the position and velocity of all body segments, their contact (impact) with external objects (including the ground), and the orientation of gravity vector (Winter, 1995).

Professional activity modifies postural strategy and this issue is particularly evident in sportsmen (Arkov et al., 2009). As well known, regular sport training induces structural and organic modifications in human body. Moreover, human balance control in an upright position depends not only on the innate reflex, but also on training capacity (Ustinova et al., 2001). Sport training increases the ability to use somatosensory and otholitic information, improving postural capabilities (Bringoux et al., 2000), which are different according to the practiced sport (Davlin, 2004; Perrin et al., 2002). A study dated 2008, identified the types of the postural subsystems involved in balance control and assessed the magnitude of their activities during classical dressage, show jumping, vaulting, and versatility riding (Schwesig et al., 2008). In general, the higher the level of practice, the more appropriate the sensory organization, and thus the higher the postural performance (Paillard et al., 2006; Vuillerme et al., 2001). Previous work suggested that both the level of activity and the type of sport may have a major impact on postural control (Schwesig et al., 2009). Several studies compared different athletes, in order to determine whether sports improved balance performance and postural control (Bressel et al., 2007; Calavalle et al., 2008; Hugel et al., 1999; Matsuda et al., 2008; Paillard et al., 2006; Weinkam et al., 2008).

\section{Postural Characteristics in Running, Cycling and Swimming}

To the knowledge of the authors, scientific evidence of the influence of the training effects among running, cycling, and swimming on stabilometric postural performances is lacking. To bridge such a gap, the authors tested the hypothesis that these 
specific types of sport have specific effects on static balance.

The herein presented study tested three groups of participants who practiced physical activities in which body attitude and postural regulation were organized in different ways. In fact, run, swim and bike training referred to environmental conditions in which feet and visual axes were used differently. Running is characterized by a movement pattern with head hold in vertical position and a sequence of foot contacts with ground. This kind of discipline is characterized by an alternation between a flying phase and a phase characterized by an alternated support of the two lower-limbs. Lower limbs work both in open and closed kinetic chain, whereas arms work always in open kinetic chain. Runners performed their physical activity on land, and they make extensive use of anti-gravity muscles during training. Moreover, they must frequently support their body weight with one leg; for these reasons they may be expected to have better one-leg stance stability than other athletes.

In contrast, swimmers work in a net condition of microgravity and in open kinetic chain: they train predominantly in water having few occasions to train anti-gravity muscles because of water buoyant force. During locomotion in water, head and body are in horizontal position and no fixed supports and reference points are available. When running, propulsion phase is provided by lower-limbs whereas arms act to balance; the opposite occurs in swimming. Foot loading reduction of swimmers could alter their proprioceptive system. In water position-sense receptors were activated while load-sense dependent receptors were inactivated (Kelly et al., 2000). As a consequence, swimmers could show a decrease in stance stability with respect to other athletes. Postural water conditioning could be comparable to those in $0 \mathrm{~g}$ situation as demonstrated in studies on Neutral Buoyancy (Andreoni et al., 2000; Toscano et al., 2004). In Space research Neutre Buoyancy Test Facility (NBTF) are conducted quite to simulate weightlessness/microgravity conditions testing activities, equipment and procedures for "ergonomic" design (ALTEC, 2012).

Finally, bikers, differently from the other two groups of athletes, maintained a sit position constrained to the bike on three fixed points (hands and pelvis) and two movable points (pedals). These athletes work in a closed kinetic chain and their plantar flexion is in the range $90^{\circ}-120^{\circ}$ degrees only supported by the metatarsus. Both upper and lower-limbs muscles were used during running and cycling but adopting different motor scheme and contraction time. For instance, the propulsion phase during cycling is based on a concentric contraction of the lengthening kinetic chain, whereas during running requires its elastic characteristic dues to the stretch shortening cycle. Literature has not yet compared these kinds of athletes in terms of their own postural strategies.

It is evident that postural control had an important role in all these physical activities (run, swimming, and cycling), but considering that each sport used lower limbs differently and received different sensorial information it is of interest to show if and how the practice of these sports induces any modification on stance stability. Hence, the aim of this study was to investigate and compare the impact of these conditioned trainings on the sensorial systems (visual, vestibular and somatosensory) of postural control.

\section{Materials and Methods}

The authors examined 26 healthy athletes, 10 runners, 10 swimmers and six bikers at a competitive level. The average age of athletes was $22 \pm 3$ years, weight $69 \pm 9 \mathrm{~kg}$, height 179.6 $\pm 5.5 \mathrm{~cm}$ and $275 \mathrm{~mm}$ foot length (ISO 9407:1991, Mondopoint). Participants practised their sport for at least three years. All the participants gave informed consent before data collection; the tests were carried out in the Motor Science Research Centre of the University of Turin, School of Exercise and Sport Science and the research was approved by the ethical committee. All the participants filled in a questionnaire aimed to assess their anthropometric parameters (age, weight, height, foot size) and practice and training characteristics (age of sport beginning, years of physical activity and training hours/week).

Each subject was free from any known pathology of the central nervous system and did not show any orthopaedic disorders either of the trunk or of the lower limbs that could affect postural performance. Since inter-subjects differences of the postural response are linked not only to individual biomechanical characteristics but also to the confidence they have with the proposed postural protocol, the recruited participants never performed postural exercises before this research to counteract this biasing factor.

A four cell platform with a sampling frequency of $20 \mathrm{~Hz}$ (Tecno-body PROKIN PK 214 P, Bergamo, Italy) was used. The calculated variables were: the average movement of the centre of pressure (COP) in the frontal plane (mm), the average movement of the centre of pressure in the sagittal plane $(\mathrm{mm})$, the average speed in anterior-posterior direction $(\mathrm{mm} / \mathrm{s})$, the average speed in medio-lateral direction $(\mathrm{mm} / \mathrm{s})$, the $90 \%$ ellipse area $\left(\mathrm{mm}^{2}\right)$, and the sway path (SP) $(\mathrm{mm})$ described by COP position during the test.

Participants were tested in a stabilometric position. In order to quantify postural control quality, the researchers chose to measure the COP displacements, which are the trajectory in time of such a point.

Participants were tested wearing their usual clothes and without shoes. Four tests were performed, two lasting 30 seconds (Gribble et al., 2007) in unipedal stance (dominant leg as a support), one with eyes open and the other with eyes closed; and two lasting 60 seconds (Nishiwaki et al., 2000; Raymakers et al., 2005) in bipedal stance with and without visual inputs.

During two-leg stance tests, the subject was barefooted (with heels touching and metatarsal phalangeal joints were in contact), with the arms along the hips. During one-leg stance tests one leg was used as a support and the other one maintained with knee flexed at $90^{\circ}$. During measurement with eyes open participants were asked to fix their gaze at a target point in the form of a black point on a white sheet located at a distance of 2 $\mathrm{m}$ at the vertical plane corresponding to eye level (Rogind et al., 2003). To minimize external disturbances, all measurements took place in a quiet, well lit room reserved for this purpose.

\section{Statistical Analysis}

Statistical analysis of the results was made with GraphPad Prism 4.0 (San Diego, California, USA). All data were reported as mean \pm standard deviation. The differences between the three groups were determined by Kruskal-Wallis test. The post hoc Dunn's tests were performed when necessary to isolate the differences. Differences within groups were investigated with the Wilcoxon test. The significance was set at a $p$ level $\leq .05$.

Finally, among stabilometric parameters, anthropometric and training data, some correlations were done (both in the single group, and in the total group of athletes), to evaluate if specific types of sport generated specific effects on static balance. 


\section{Results}

The results of Kruskal-Wallis test indicated no significant differences in the anthropometric and training characteristics of the recruited athletes (as reported in Table 1).

Statistical significant differences between groups were found only for the variable "age of physical activity beginning" ( $p$ $<.05)$. This result showed that swimmers begun their sport earlier at $(8 \pm 3$ years $)$, than the other two groups at $(15 \pm 6$ years; $p<.05$ ). Other differences were reported for the variable "number of training hours for week", where bikers showed the greatest value $(19 \pm 3$ hours $)(p<.01)$. No statistically significant differences were observed, during monopodalic test in eyes open (EO) and in eyes closed (EC) conditions among the three groups, whereas some significant differences were observed during bipodalic test with and without visual inputs.

Bikers showed more posterior (negative) sway of the COP, in particular in comparison with runners both in EO condition $(p<.05)$ and in EC condition $(p<.05)$. In fact they reported greater negative median y COP values than others two groups, as illustrated in Figures $\mathbf{1}$ and $\mathbf{2}$.

Moreover, bikers showed the best postural stability associated with the best body control in A-P direction and reported average speeds lower than runners and swimmers both in EO condition $(p<.01)$ and in EC condition $(p<.05)$. The best body control in M-L direction in EO condition $(p<.05)$ was also observed in the bikers (as reported in Figures 3-5).

Perimeter length was found the shortest during tests with visual inputs for the bikers whereas swimmers showed the worst body control during analysed stabilometric trials $(p<.01)$ (as illustrated in Figure 6).

Table 1.

Synthesis of anthropometric, practice and training characteristics of analyzed athletes and the results of Kruskal-Wallis test among the three groups. Post hoc statistical significant differences are evidenced by ${ }^{*}(p$ $<.05)$ and by ${ }^{* *}(p<.01)$ and n.s. (not significant). R: (runners). S: (swimmers). B: (bikers).

\begin{tabular}{|c|c|c|c|c|c|c|c|c|c|}
\hline & & 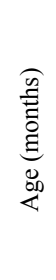 & 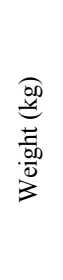 & 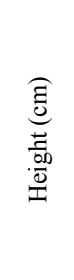 & 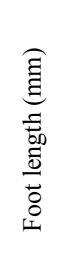 & 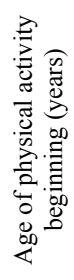 & 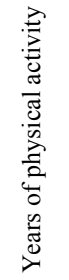 & 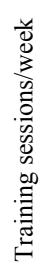 & 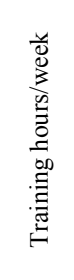 \\
\hline \multirow{4}{*}{ 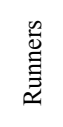 } & Minimum & 218 & 54 & 174 & 260 & 8 & 3 & 3 & $4.5 \mathrm{~h}$ \\
\hline & Maximum & 333 & 86 & 189 & 286 & 17 & 16 & 11 & $22 \mathrm{~h}$ \\
\hline & Mean & 253 & 65 & 179 & 273 & 13 & 7.5 & 5 & $8.5 \mathrm{~h}$ \\
\hline & Std. Deviation & \pm 39 & \pm 10 & \pm 5 & \pm 1.5 & \pm 3 & \pm 4 & \pm 3 & \pm 5.0 \\
\hline \multirow{4}{*}{ 岕 } & Minimum & 226 & 60 & 173 & 254 & 5 & 6 & 3 & $3.5 \mathrm{~h}$ \\
\hline & Maximum & 367 & 94 & 192 & 286 & 13 & 24 & 10 & $20 \mathrm{~h}$ \\
\hline & Mean & 285 & 73 & 1789 & 267 & 8 & 15 & 6 & $12 \mathrm{~h}$ \\
\hline & Std. Deviation & \pm 51 & \pm 9 & \pm 5.51 & \pm 2 & \pm 3 & \pm 6 & \pm 2 & \pm 6.0 \\
\hline \multirow{4}{*}{$\frac{n}{2}$} & Minimum & 244 & 67 & 172 & 257 & 7 & 4 & 5.5 & $13.5 \mathrm{~h}$ \\
\hline & Maximum & 320 & 77 & 188 & 279 & 21 & 15 & 7 & $21 \mathrm{~h}$ \\
\hline & Mean & 269 & 71 & 182 & 273 & 13 & 9 & 6.5 & $19 \mathrm{~h}$ \\
\hline & Std. Deviation & \pm 27 & \pm 4 & \pm 6 & \pm 1.5 & \pm 6 & \pm 5 & \pm .6 & \pm 3.0 \\
\hline 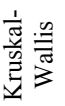 & $\begin{array}{l}\text { Post hoc } \\
p \text { values }\end{array}$ & n.s & n.s. & n.s. & n.s. & $\mathrm{R}<\mathrm{S}$ & $\mathrm{R}<\mathrm{S}^{2}$ & n.s & $\mathrm{R}<{ }_{* *} \mathrm{~B}$ \\
\hline
\end{tabular}

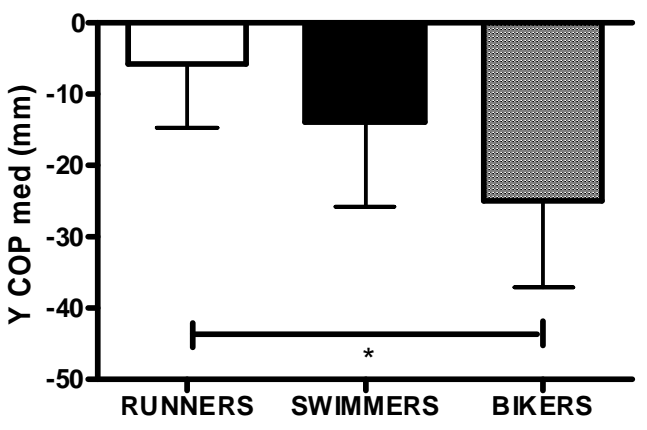

Figure 1.

Kruskal-Wallis test; differences between groups during bipedal stance in E.O. condition for Y COP med variable. Post hoc significance difference was evidenced by ${ }^{*}(p$ $<.05)$.

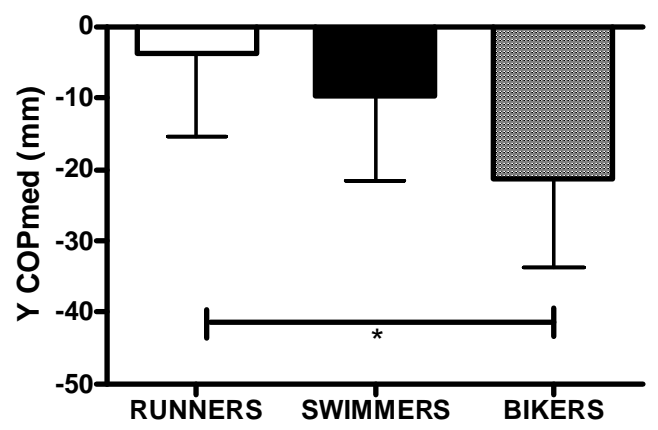

Figure 2.

Kruskal-Wallis test; differences between groups during bipedal stance in E.C. condition for Y COP med variable. Post hoc significance difference was evidenced by ${ }^{*}(p$ $<.05)$.

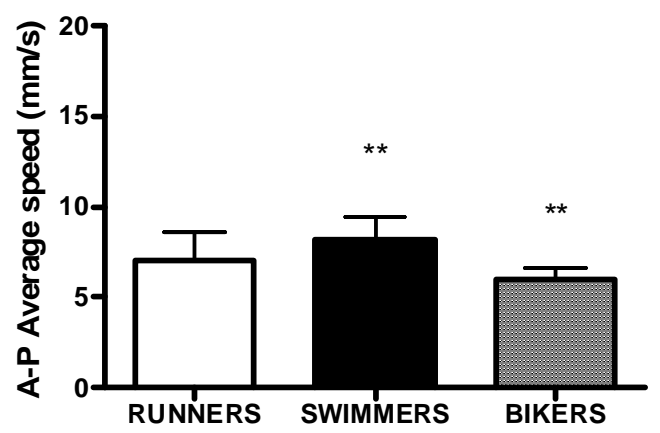

Figure 3.

Kruskal-Wallis test; differences between groups during bipedal stance in E.O. condition for A-P average speed variable. Post hoc significance difference was evidenced by ${ }^{* *}(p<.01)$.

No statistically significant differences were reported among the three groups for other stabilometric parameters.

The Wilcoxon test (Table 2) indicated statistically significant differences between EO and EC trials within each group both in bipodalic and in monopodalic tests. During EC trials all groups reported their worst balance stability in comparison with EO trials, but such a difference was less marked in bikers; in fact for all the stabilometric variables this group showed less differences between the two trials in different sensory conditions $(p<.05)$. 


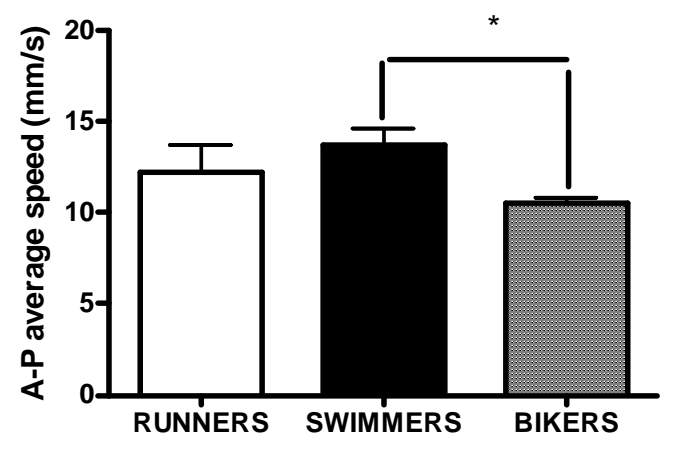

Figure 4.

Kruskal-Wallis test; differences between groups during bipedal stance in E.C. condition for A-P average speed variable. Post hoc significance difference was evidenced by $^{*}(p<.05)$.

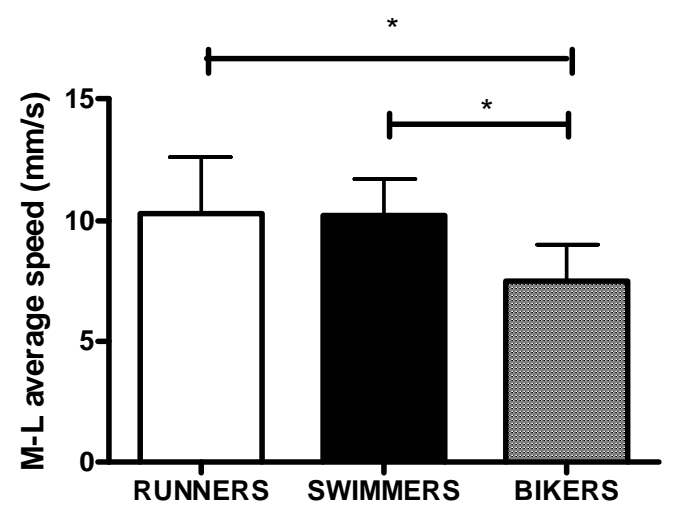

Figure 5.

Kruskal-Wallis test; differences between groups during bipedal stance in E.O. condition for M-L average speed variable. Post hoc significance differences were evidenced by ${ }^{*}(p<.05)$.

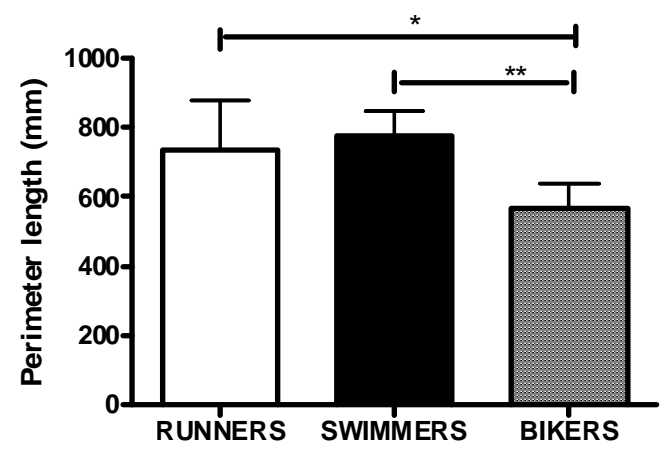

Figure 6.

Kruskal-Wallis test; differences between groups during bipedal stance in E.O. condition for perimeter length variable. Post hoc significance differences were evidenced by ${ }^{*}(p<.05)$ and by ${ }^{* *}(p<.01)$.

The analysis was carried out pooling together all the athletes (bikers, swimmers and runners) (Tables 3 and 4). It was found as follows:

1) Average speed in A-P plane was inversely correlated, in bipodalic test in EC condition, with age of sport beginning ( $p$ $<.05)$ and, in monopodalic test in EO trials, with training hours a week $(p<.05) .2)$ Average speed in M-L plane was inversely
Table 2.

Wilcoxon test results. E.O. and E.C. conditions were compared within each group in bipodalic and monopodalic tests. Statistical significant differences were evidenced by ${ }^{*}(p<.05),{ }^{* *}(p<.01)$ and by n.s. (not significant). All differences between variables recorded during E.O and E.C. conditions were found greater in E.C. than in E.O. trials in all groups.

\begin{tabular}{|c|c|c|c|c|c|}
\hline & $\begin{array}{l}\text { Wilcoxon test } \\
\text { E.O. vs E.C. } \\
\text { conditions }\end{array}$ & 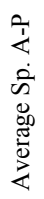 & 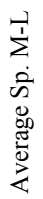 & 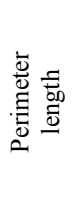 & 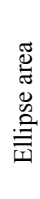 \\
\hline \multirow{2}{*}{ Runners } & Bipodalic test & ${ }^{* * *}$ & ${ }^{* *}$ & ** & n.s. \\
\hline & Monopodalic test & $* *$ & $* *$ & ** & ** \\
\hline \multirow[b]{2}{*}{ Swimmers } & Bipodalic test & $* *$ & $* *$ & ${ }^{* *}$ & $* *$ \\
\hline & Monopodalic test & ** & $* *$ & ** & ** \\
\hline \multirow{2}{*}{ Bikers } & Bipodalic test & * & $*$ & * & n.s. \\
\hline & Monopodalic test & * & ${ }^{*}$ & * & * \\
\hline
\end{tabular}

Table 3.

Correlations among stabilometric parameters, anthropometric and training data during E.O. and E.C. bipodalic tests. Only parameters for which were found significative correlation are reported in the table. A represents the whole group of 26 analysed athletes. R: runners. S: swimmers. B: bikers. The first value represents the $r$ value and the second one the $p$ value of the correlations.

\begin{tabular}{|c|c|c|c|c|c|c|}
\hline & $\begin{array}{l}\frac{5}{60} \\
\frac{60}{00} \\
3\end{array}$ & 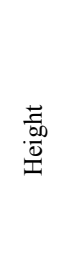 & 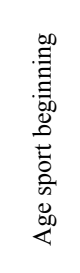 & 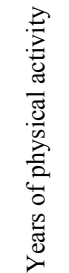 & 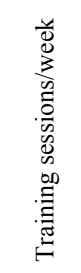 & 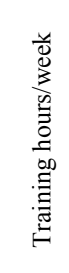 \\
\hline $\begin{array}{c}\text { Aver. Sp. } \\
\text { A-P } \\
\text { EC condition }\end{array}$ & & & $\begin{array}{c}\mathrm{A} \\
-.421 \\
.032\end{array}$ & $\begin{array}{c}\mathrm{B} \\
.845 \\
.033\end{array}$ & $\begin{array}{c}\mathrm{B} \\
.921 \\
.017\end{array}$ & $\begin{array}{c}\mathrm{B} \\
.921 \\
.017\end{array}$ \\
\hline $\begin{array}{l}\text { Aver. Sp. } \\
\text { M-L } \\
\text { EO condition }\end{array}$ & $\begin{array}{c}\mathrm{S} \\
.706 \\
.022 \\
\mathrm{~B} \\
.845 \\
.033\end{array}$ & & & & & $\begin{array}{c}\mathrm{A} \\
-.525 \\
.005\end{array}$ \\
\hline $\begin{array}{c}\text { Aver. Sp. } \\
\text { M-L } \\
\text { EC condition }\end{array}$ & & & & & & $\begin{array}{c}\mathrm{A} \\
-.439 \\
.024\end{array}$ \\
\hline $\begin{array}{l}\text { Perimeter } \\
\text { Length } \\
\text { EO condition }\end{array}$ & & $\begin{array}{c}\mathrm{S} \\
.669 \\
.035\end{array}$ & & & $\begin{array}{c}\mathrm{A} \\
-.395 \\
.046 \\
\mathrm{~S} \\
-.654 \\
.040\end{array}$ & $\begin{array}{c}\mathrm{A} \\
-.551 \\
.004 \\
\mathrm{~S} \\
-.719 \\
.019\end{array}$ \\
\hline $\begin{array}{l}\text { Perimeter } \\
\text { Length } \\
\text { EC condition }\end{array}$ & & & & & & $\begin{array}{c}\mathrm{A} \\
-.424 \\
.031\end{array}$ \\
\hline $\begin{array}{c}\text { Ellipse } \\
\text { Area } \\
\text { EO } \\
\text { condition }\end{array}$ & $\begin{array}{c}\mathrm{S} \\
.650 \\
.042 \\
\mathrm{~A} \\
.408 \\
.039\end{array}$ & $\begin{array}{c}\mathrm{R} \\
.741 \\
.017 \\
\mathrm{~A} \\
.576 \\
.002\end{array}$ & & & & \\
\hline
\end{tabular}


Table 4.

Correlations among stabilometric parameters, anthropometric and training data during E.O. and E.C. monopodalic tests. Only parameters for which significative correlation were found are reported in the table. A represents the whole group of 26 analysed athletes. R runners. S: swimmers. B: bikers. The first value represents the $r$ value and the second one the $p$ value of the correlations.

\begin{tabular}{|c|c|c|c|c|c|c|c|}
\hline & 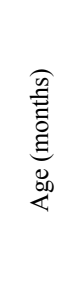 & $\begin{array}{l}\overrightarrow{5} \\
\frac{500}{0} \\
3\end{array}$ & 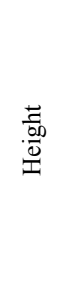 & 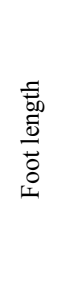 & 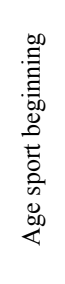 & 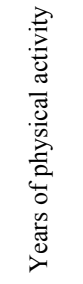 & 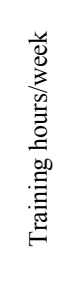 \\
\hline \multicolumn{8}{|l|}{ Aver. Sp. } \\
\hline A-P & $\mathrm{R}$ & & & $\mathrm{S}$ & & & A \\
\hline EO & -.757 & & & .651 & & & -.449 \\
\hline condition & .015 & & & .049 & & & .021 \\
\hline \multicolumn{8}{|l|}{ Aver. Sp. } \\
\hline M-L & $\mathrm{R}$ & & & & & & A \\
\hline $\mathrm{EO}$ & -.679 & & & & & & -.462 \\
\hline condition & .035 & & & & & & .018 \\
\hline \multicolumn{8}{|l|}{ Perimeter } \\
\hline Length & $\mathrm{R}$ & & & $\mathrm{S}$ & & & A \\
\hline $\mathrm{EO}$ & -.663 & & & .683 & & & -.530 \\
\hline condition & .044 & & & .035 & & & .006 \\
\hline \multicolumn{8}{|c|}{$\mathrm{S}$} \\
\hline Ellipse & & & .693 & & & & \\
\hline Area & & & .031 & & & & \\
\hline \multirow{3}{*}{ EO condition } & & A & A & & $\mathrm{S}$ & & \\
\hline & & .441 & .553 & & .769 & & \\
\hline & & .024 & .003 & & .013 & & \\
\hline Ellipse & & & & & $\mathrm{R}$ & $\mathrm{R}$ & \\
\hline Area & & & & & .899 & -.821 & \\
\hline EC condition & & & & & .001 & .005 & \\
\hline
\end{tabular}

correlated, in bipodalic test with EO $(p<.01)$, and in EC ( $p$ $<.05)$ and in monopodalic test with EO $(p<.01)$, with training hours a week. 3) Perimeter length was inversely correlated, in bipodalic test with EO condition, with number of training session a week $(p<.05)$ and with hours of training session a week $(p<.01)$, and, this last variable was inversely correlated also in bipodalic test with EC $(p<.05)$ and in monopodalic test with EO $(p<.01) .4)$ Ellipse area was positively correlated with weight $(p<.05)$ and height $(p<.01)$, both in bipodalic test and in monopodalic test with EO.

When the analysis was carried out within each group:

In runners, it was found that: 1) age, in monopodalic test with EO, was inversely correlated with average speeds in A-P $(p<.05)$, M-L $(p<.05)$ and perimeter length $(p<.05)$; 2$)$ ellipse area, in bipodalic test with EO, was positively correlated with height $(p<.05)$, such as in Athletes group, whereas was inversely correlated in bipodalic test with EC and, in monopodalic test with EC, with age of sport beginning $(p<.001)$ and years of physical activity $(p<.01)$.

In swimmers, it was found that: 1) average speed in A-P plane, during monopodalic test with EO, was positively correlated with foot size $(p<.05) ; 2)$ average speed in M-L, during bipodalic test with EO, was positively correlated with weight ( $p$ $<.05$ ), such as in bikers. 3) Perimeter length was positively correlated with height $(p<.05)$, in bipodalic test with EO, and with foot size $(p<.05)$, in monopodalic test with EO, whereas was inversely correlated with number of training sessions for week $(p<.05)$ and with training hours $(p<.05)$, in bipodalic test with EO, such as in athletes group. 4) Ellipse area, in bipodalic test with EO, was positively correlated with weight ( $p$ $<.05)$, such as in the athletes group as a whole, whereas, in monopodalic test with EO, with age of sport beginning $(p<.05)$ and with height $(p<.05)$.

In bikers, it was found that: 1) average speed in A-P was positively correlated, in bipodalic test with EC, with years of physical activity $(p<.05)$, number of training $(p<.05)$, and with hours of training sessions a week $(p<.05)$. 2) Average speed in M-L plane, in bipodalic test with EO was positively correlated with weight $(p<.05)$, such as in the swimmers group.

\section{Discussion and Conclusion}

The capacity to use sensory information varied among subjects; in general, the practice of physical and sporting activities (type and level of practice) improved postural balance (Davlin, 2004; Guskiewicz et al., 2001; Hugel et al., 1999; Paillard et al., 2007; Perrin et al., 2002). Postural efficiency increased thanks to the sensibility of the different sensors and to the development of a sensory hierarchy related to proprioceptive preference (Gauchard et al., 1999; Mesure et al., 1997; Perrin et al., 1998). The herein study revealed that specific types of sport showed specific effects on static balance which can be quantitatively assessed. In fact, investigating the influence of three out of the more played sport (such as running, cycling, and swimming) on sensorial systems of postural control, findings showed that bikers reported the best postural stability and swimmers the worst. In 1999, some authors (Hahn et al., 1999) failed to demonstrate an association between postural stability and work or leisure activities in young people. They demonstrated that unipedal balance test was not associated with gender and age, but was positively associated with hours per week of sport activity (in that case basketball). These findings are similar to the correlations herein presented revealing that load training (number of training sessions, hours of training sessions) positively influences stabilometric parameters of athletes group, in particular on M-L average speed and on perimeter length with a correlation in all tests with the only exception for monopodalic test with eyes closed.

We shall remember that all the questions regarding the effects of postures in a gravitational field are related to what we may call a "gravitational revolution" as the Primates spine rotated appreciatively $90^{\circ}$ in about $60 \mathrm{MY}$ but only recently $(\approx 4$ MY) Hominids acquired the terrestrial upright posture. Such change may be taken as a simulation of an adaptation to a quite different gravity environment (Gamba et al., 2001).

In bikers, load training and the years of activity were found to have a negative effect on A-P average speed without visual inputs during bipodalic test, probably even if they showed the best postural performances, these kind of athletes had a less ability in body control in A-P direction, because in this plane they were constrained on the bike with two fixed points (one on saddle and the other on handle). Another explanation of this finding could be the fact that bikers maintained balance by watching the profile of the road, the back wheel, and the shoulders of the cyclists in front of them (Lion et al., 2009). Moreover, the optimal position on bike is characterized by a load distribution with $40 \%$ on anterior wheel and $60 \%$ on posterior wheel. According to that, findings showed more posterior sway of the COP in bikers, in particular in comparison with runners, 
both in EO condition and in EC conditions. During bipodalic test (in EO and EC conditions) statistically significant differences in COP sways, average speeds in A-P and M-L planes and perimeter length were found, whereas during monopodalic test no statistically significant differences were obtained in the three analyzed groups.

This finding can be explained since the three analyzed sports are symmetrical and characterized by cyclic actions; therefore, bipodalic EO tests could be considered more specific for these athletes than one-legged stance test. In fact, monopodalic static stance cannot be considered a training position for these athletes, and it was found the most stressful, in particular with eyes closed. This finding was confirmed also by other authors (Asseman et al., 2008; Paillard et al., 2006; Perrin et al., 2002). During double stance test bikers showed more postural stability than other athletes, in particular swimmers, with statistically significant differences in A-P direction with and without visual inputs, in M-L direction and in perimeter length with EO. Their ability to maintain the bike in balance, in particular in M-L direction, could explain such a specific postural performance. Furthermore, maintaining an appropriate posture on bike seems to be essential to ensure the highest performances (Duc et al., 2008). The elimination of eyesight during the tests resulted in a marked increase in postural sway on the force platform for all athletes, diminishing visual feedback with eyes closed conditions consistently decreased postural stability in comparison to opened conditions.

Findings herein presented are similar to those from another study (Riemann et al., 1999); moreover, data from bikers suggested reduced differences between the two trials in EO and EC conditions, supporting the fact that visual inputs were much more important for swimmers and runners compared to the bikers. The role of vision in bikers was studied in 2009 (Lion et al., 2009). It was shown that balance-related visual information was better used by bikers who mostly practiced on-road cycling, whereas, proprioceptive information was better used by mountain bikers, who mostly practiced off-road cycling. The practice of swimming in elderly people (Hsu, 2010), was shown to improve balance function in difficult conditions in contrast to other elderly athletes. Contrary to that study, swimmers herein showed the worst postural sways particularly in comparison with runners. These findings may be related to the fact that participants recruited in this study were younger and spent the most part of their physical training in aquatic environment assuming horizontal position. Sensorial information to the central nervous system was altered during swimming due to the counter balanced force of gravity, the lack of uprightness and ground support. These modifications induce a re-organization of the sensorimotor system that provokes the development of a specific aquatic coordination. In the present study considerable differences were observed in the adaptability of postural control during stabilometric trials between athletes from different disciplines. Such differences in postural control abilities may depend on individual athletic background and consequently on training characteristics.

These aspects modify postural balance capabilities respect to postural demand typical of stable environment $(g=9.81 \mathrm{~m} / \mathrm{s})$ that modify the capacity of managing the balance than required by the simple force of gravity in a condition of static upright posture. These results provide additional information in support of the ability of stabilometric techniques to identify inter-subject differences. The current study provides evidence that sig- nificant differences on stabilometric performances can be observed and quantified in bikers, runners and swimmers. As a consequence, the practice of different sport specialties can impact in different way on balance control. Training induces modifications on postural control mechanisms: athletes from different disciplines scored different stabilometric performances, because each sport develops specific postural adaptations. Sports, as extreme conditions of human activity, are one of the most valid fields of experimentation for advanced physical Anthropology researches.

\section{Acknowledgements}

The Authors are grateful to the participants in the experimental session. In particular we wish to thank the participants of this study. A special acknowledgment goes to Prof. M. Masali for valuable advice and openness to considerations on aspects of the relationship between man and environment extragravitational conditions! Finally, we wish to thank the company Tecnobody, Bergamo, Italy that provided the equipment used in this investigation.

\section{REFERENCES}

\section{ALTEC (2012).}

http://www.esa.int/Our_Activities/Human_Spaceflight/Human_Spac eflight_Research/ALTEC___Neutral_Buoyancy_Test_Facility_NBT $\mathrm{F}$

Andreoni, G., Rigotti, C., Baroni, G., Ferrigno, G., Colford, N. A., \& Pedotti, A. (2000). Quantitative analysis of neutral body posture in prolonged micro-gravity. Gait and Posture, 12, 235-242. http://dx.doi.org/10.1016/S0966-6362(00)00088-6

Arkov, V. V., Abramova, T. F., Nikitina, T. M., Ivanov, V. V., Suprun, D. V., Shkurnikov, M. U. et al. (2009). Comparative study of stabilometric parameters in sportsmen of various disciplines. Bulletin of Experimental Biology and Medicine, 147, 233-235. http://dx.doi.org/10.1007/s10517-009-0482-6

Asseman, F. B., Caron, O., \& Cremieux, J. (2008). Are there specific conditions for which expertise in gymnastics could have an effect on postural control and performance? Gait Posture, 27, 76-81. http://dx.doi.org/10.1016/j.gaitpost.2007.01.004

Bressel, E., Yonker, J. C., Kras, J., \& Heath, E. M. (2007). Comparison of static and dynamic balance in female collegiate soccer, basketball, and gymnastics athletes. Journal of Athletic Training, 42, 42-46.

Bringoux, L., Marin, L., Nougier, V., Barraud, P. A., \& Raphel, C. (2000). Effects of gymnastics expertise on the perception of body orientation in the pitch dimension. Journal of Vestibular Research, 10, 251-258.

Calavalle, A. R., Sisti, D., Rocchi, M. B., Panebianco, R., Del Sal, M., \& Stocchi, V. (2008). Postural trials: Expertise in rhythmic gymnastics increases control in lateral directions. European Journal of Applied Physiology, 104, 643-649. http://dx.doi.org/10.1007/s00421-008-0815-6

Davlin, C. D. (2004). Dynamic balance in high level athletes. Percept Mot Skills, 98, 1171-1176.

Dubois, K. (1994). Dance and weightlessness: Dancer's training and adaptation problems in microgravity. Leonardo, 27, 57-64. http://dx.doi.org/10.2307/1575951

Delattre, A., \& Fenart, R. (1960). L'hominisation du crãine. Paris: Editions du Centre National de la Recherche Scientifique.

Duc, S., Bertucci, W., Pernin, J. N., \& Grappe, F. (2008). Muscular activity during uphill cycling: Effect of slope, posture, hand grip position and constrained bicycle lateral sways. Journal of Electromyography \& Kinesiology, 18, 116-127. http://dx.doi.org/10.1016/j.jelekin.2006.09.007

Gamba, M., Lombard, E., Masali, M., Ferrino, M., Gaia, E., \& Duca, S. (2001). Evolution of human posture in microgravitational environments: The primatological bases. Folia Primatologica, 72, 128-152.

Gauchard, G. C., Jeandel, C., Tessier, A., \& Perrin, P. P. (1999). Bene- 
ficial effect of proprioceptive physical activities on balance control in elderly human subjects. Neuroscience Letters, 273, 81-84.

http://dx.doi.org/10.1016/S0304-3940(99)00615-1

Gould, S. J. (1990). An earful of jaw. Natural History, 3190, 12-23.

Gould, S. J. (2010). Exaptation: A crucial tool for an evolutionary psychology. Journal of Social Issues, 47, 43-65.

http://dx.doi.org/10.1111/j.1540-4560.1991.tb01822.x

Gould, S. J., \& Vrba, E. S. (1982). Exaptation-A missing term in the science of form. Paleobiology, 8, 4-15.

Gribble, P. A., Tucker, W. S., \& White, P. A. (2007). Time-of-day influences on static and dynamic postural control. Journal of Athletic Training, 42, 35-41.

Guskiewicz, K. M., Ross, S. E., \& Marshall, S. W. (2001). Postural stability and neuropsychological deficits after concussion in collegiate athletes. Journal of Athletic Training, 36, 263-273.

Hahn, T., Foldspang, A., Vestergaard, E., \& Ingemann-Hansen, T. (1999). One-leg standing balance and sports activity. Scandinavian Journal of Medicine \& Science in Sports, 9, 15-18. http://dx.doi.org/10.1111/j.1600-0838.1999.tb00201.x

Harmon, K. (2013). Shattered ancestry. Scientific American, 308, 4249. http://dx.doi.org/10.1038/scientificamerican0213-42

Hsu, H. C., Chou, S. W., Chen, C. P., Wong, A. M., Chen, C. K., \& Hong, J. P. (2010). Effects of swimming on eye hand coordination and balance in the elderly. The Journal of Nutrition Health and Aging, 14, 692-695. http://dx.doi.org/10.1007/s12603-010-0134-6

Hugel, F., Cadopi, M., Kohler, F., \& Perrin, P. (1999). Postural control of ballet dancers: A specific use of visual input for artistic purposes. International Journal of Sports Medicine, 20, 86-92. http://dx.doi.org/10.1055/s-2007-971098

Kelly, B. T., Roskin, L. A., Kirkendall, D. T., \& Speer, K. P. (2000). Shoulder muscle activation during aquatic and dry land exercises in nonimpaired subjects. Journal of Orthopaedic \& Sports Physical Therapy, 30, 204-210. http://dx.doi.org/10.2519/jospt.2000.30.4.204

Lion, A., Gauchard, G. C., Deviterne, D., \& Perrin, P. P. (2009). Differentiated influence of off-road and on-road cycling practice on balance control and the related-neurosensory organization. Journal of Electromyography \& Kinesiology, 19, 623-630. http://dx.doi.org/10.1016/j.jelekin.2008.03.008

Manchester, D., Woollacott, M., Zederbauer-Hylton, N., \& Marin, O. (1989). Visual, vestibular and somatosensory contributions to balance control in the older adult. The Journals of Gerontology, 44, M118-M127. http://dx.doi.org/10.1093/geronj/44.4.M118

Masali, M., Rosato, M. R., Tinto, A., Schlacht, I. L., Ferrino, M., \& Micheletti Cremasco, M. (2010a). Exploiting rhythmic gymnastic in microgravity. Journal of Sports Medicine and Physical Fitness, 50.

Masali, M., Ferrino, M., Argenta, M., \& Micheletti Cremasco, M. (2010b). Chapter 13. Anthropology: Physical and cultural adaptation in outer space. In: H. Benaroya, (Ed.), Lunar settlements (pp. 165-173). Boca Raton, FL: CRC Press, Taylor \& Francis Group.

Matsuda, S., Demura, S., \& Uchiyama, M. (2008). Centre of pressure sway characteristics during static one-legged stance of athletes from different sports. Journal of Sports Science, 26, 775-779. http://dx.doi.org/10.1080/02640410701824099

Mesure, S., Amblard, B., \& Cremieux, J. (1997). Effect of physical training on head-hip co-ordinated movements during unperturbed stance. Neuroreport, 8, 3507-3512. http://dx.doi.org/10.1097/00001756-199711100-00018

Nishiwaki, Y., Takebayashi, T., Imai, A., Yamamoto, M., \& Omae, K. (2000). Difference by instructional set in stabilometry. Journal of Vestibular Research, 10, 157-161.

Paillard, T., Montoya, R., \& Dupui, P. (2007). Postural adaptations specific to preferred throwing techniques practiced by competition-level judoists. Journal of Electromyography \& Kinesiology, 17, 241-244. http://dx.doi.org/10.1016/j.jelekin.2006.01.006

Paillard, T., Noe, F., Riviere, T., Marion, V., Montoya, R., \& Dupui, P. (2006). Postural performance and strategy in the unipedal stance of soccer players at different levels of competition. Journal of Athletic Training, 41, 172-176.

Perrin, P., Deviterne, D., Hugel, F., \& Perrot, C. (2002). Judo, better than dance, develops sensorimotor adaptabilities involved in balance control. Gait Posture, 15, 187-194.

http://dx.doi.org/10.1016/S0966-6362(01)00149-7

Perrin, P., Schneider, D., Deviterne, D., Perrot, C., \& Constantinescu, L. (1998). Training improves the adaptation to changing visual conditions in maintaining human posture control in a test of sinusoidal oscillation of the support. Neuroscience Letters, 245, 155-158. http://dx.doi.org/10.1016/S0304-3940(98)00208-0

Raymakers, J. A., Samson, M. M., \& Verhaar, H. J. (2005). The assessment of body sway and the choice of the stability parameter(s). Gait Posture, 21, 48-58. http://dx.doi.org/10.1016/i.gaitpost.2003.11.006

Riemann, B., Caggiano, N., \& Lephart, S. (1999). Examination of a clinical method of assessing postural control during a functional performance task. Journal of Sport Rehabilitation, 2, 171-183.

Rogind, H., Simonsen, H., Era, P., \& Bliddal, H. (2003). Comparison of Kistler 9861A force platform and Chattecx Balance System for measurement of postural sway: Correlation and test-retest reliability. Scandinavian Journal of Medicine \& Science in Sports, 13, 106-114. http://dx.doi.org/10.1034/j.1600-0838.2003.01139.x

Rosato, M. R., Tinto, A., Masali, M., Schlacht, I. L., \& Micheletti Cremasco, M. (2012). An unfeasible experiment: ZER0GYM. Current state and prospects. Journal of Biological Research, 85, 280-281.

Schlacht, I. L., Brambillasca, S., \& Birke, H. (2009a). Color perception in microgravity conditions: The results of CROMOS parabolic flight experiment. Microgravity Science and Technology, 21, 21-30.

Schlacht, I. L., Rötting, M., Masali, M., \& Micheletti Cremasco, M. (2009b). Human factors in space mission. In A. Lichtenstein, C. Stößel, \& C. Clemens (a cura di) (Eds.), Der Mensch im Mittelpunkt technischer Systeme. 8. Berliner werkstatt-mensch-maschine-systeme. [CD] (pp. 326-330). Düssedorf: Edizione VDI Verlag.

Schlacht, I. L., Masali, M., Rötting, M., Micheletti Cremasco, M., \& Ono, A. (2009c). Space station visual design for the astronauts reliability. Proceeding of 60th International Astronautical Congress. Red Hook, NY: Curran Associates, Inc. http://www.iafastro.net/download/congress/IAC-09/DVD/full/

Schwesig, R., Kluttig, A., Leuchte, S., Becker, S., Schmidt, H., \& Esperer, H. D. (2009). The impact of different sports on posture regulation. Sportverletz Sportschaden, 23, 148-154. http://dx.doi.org/10.1055/s-0028-1109576

Schwesig, R., Sannemuller, K., Kolditz, R., Hottenrott, K., Becker, S., \& Esperer, H. D. (2008). Specific riding styles are associated with specific effects on bodily posture control. Sportverletz Sportschaden, 22, 93-99. http://dx.doi.org/10.1055/s-2008-1027394

Tinto, A., Rosato, M. R., Schlacht, I. L., Masali, M., \& Micheletti Cremasco, M. (2012). Differences in the perception of sound/rhythm and the effect on gymnastics performance in microgravity (the zer0gmn project). Proceeding of 63th International Astronautical Congress, Red Hook, NY: Curran Associates, Inc., 94-97. http://www.iafastro.net/download/congress/IAC-12/DVD/full/

Toscano, E., Fubini, E., \& Gaia, E., (2004). Microgravity simulation: Physical and psychological workload evaluation tests in an underwater environment. Applied Ergonomics, 35, 383-391. http://dx.doi.org/10.1016/j.apergo.2004.02.007

Ustinova, K. I., Chernikova, L. A., Ioffe, M. E., \& Sliva, S. S. (2001). Impairment of learning the voluntary control of posture in patients with cortical lesions of different locations: The cortical mechanisms of pose regulation. Neurosci Behav Physiol, 31, 259-267. http://dx.doi.org/10.1023/A:1010326332751

Vuillerme, N., Danion, F., Marin, L., Boyadjian, A., Prieur, J. M., Weise, I. et al. (2001). The effect of expertise in gymnastics on postural control. Neuroscience Letters, 303, 83-86. http://dx.doi.org/10.1016/S0304-3940(01)01722-0

Weinkam, P., Zimmermann, J., Sagle, L. B., Matsuda, S., Dawson, P. E., Wolynes, P. G. et al. (2008). Characterization of alkaline transitions in ferricytochrome c using carbon-deuterium infrared probes. Biochemistry, 47, 13470-13480.

http://dx.doi.org/10.1021/bi801223n

Winter, D. A. (1995). Human balance and posture control during standing and walking. Gait and posture, 3, 193-214. http://dx.doi.org/10.1016/0966-6362(96)82849-9 